\title{
Evaluation of immunization status and factors responsible for drop outs in primary immunization in children between 1-2 years - a hospital based study
}

\author{
N Madhavi', D Manikyamba ${ }^{2}$ \\ ${ }^{1}$ Dr. N. Madhavi, Associate Professor, Department of Pediatrics, Guntur Medical College, Guntur, Andhra Pradesh, \\ ${ }^{2}$ Dr. D. Manikyamba, Professor \& HOD, Department of Pediatrics, Rangaraya Medical College, Kakinada, Andhra \\ Pradesh, India.
}

Address for Correspondence: Dr. N. Madhavi, Email: madhaviped205@ gmail.com

\begin{abstract}
Introduction: Immunization programme has been a major cost-effective public health intervention for child survival. Despite implementation of immunization programme since 1978 by Govt of India (GOI), the coverage of immunization is not satisfactory due to various socio economic factors influencing vaccination coverage. Aim: To determine the coverage and to identify the various factors influencing primary immunization in children. Methods: Hospital based cross sectional study was conducted from January 2012 to September 2013 by interviewing parents of 2000 children of 1-2 yr age attending OPD and Children`s ward in Govt General Hospital, Kakinada, AP. Socio demographic factors and details of immunization status of the children and the reasons for dropouts were noted. The child who received all primary doses of BCG, DPT, Hepatitis B, OPV and Measles mentioned in National immunization schedule is considered fully immunised. Child who missed even a single dose and who did not receive even a single dose of any vaccine is considered partially immunised and un-immunised respectively. Percentages and Chi square test were used for statistical analysis. Results: Overall, 1810 were fully immunised (90.5\%), 186 were partially immunised (9.3\%) and 4 were unimmunised. Type of family and education of parents had a significant role in the immunization coverage of children whereas gender, religion and residence of children were not found to have significant impact on immunization status. Unwell child, lack of knowledge and migration to other places were found to be major contributing factors for poor immunization. Conclusion: Regular health education of all sections of the community especially the mothers to increase awareness of childhood immunization and addressing the issues of dropouts and poor accessibility is urgently required for better and equitable coverage of across all regions of the country.
\end{abstract}

Keywords: Immunization status, Coverage, Dropout, Socio demographic factors.

\section{Introduction}

India is the second most populous country in the world with $3 / 4^{\text {th }}$ of our population coming from a rural background with poor socio economic status and illiteracy. Children below 5 yr constitute $12-15 \%$ of this population. Because of such large population, the number of diseases is also on the rise and most of such diseases can be prevented. About $14^{\text {th }}$ of Under 5 mortality is due to vaccine preventable diseases [1]. Keeping this in mind GOI launched Expanded Programme of Immunization (EPI) in 1978 and made it mandatory that all children should be immunised

Manuscript received: $3^{\text {rd }}$ April 2016

Reviewed: $14^{\text {th }}$ April 2016

Author Corrected; $27^{\text {th }}$ April 2016

Accepted for Publication: $12^{\text {th }}$ May 2016 against the vaccine preventable diseases [2]. Later in 1985, the Universal Immunization Programme (UIP) was launched in India to protect all infants (0-12 mo) against 6 serious but preventable diseases, namely tuberculosis, diphtheria, pertussis, tetanus, poliomyelitis and measles. The objective of this programme was to fully vaccinate atleast $85 \%$ of all infants. In subsequent years, the goal of UIP was raised to ensure $100 \%$ coverage of all eligible children with one dose of BCG, 3 doses of DPT and OPV and one dose of measles vaccine.

After the introduction of childhood vaccination, there is a definite fall in IMR and Under 5 mortality. Though, 
there is a reduction in disease burden of vaccinepreventable diseases through childhood immunization in our country, it is still unacceptably high, in comparison to developed countries and also many developing countries. One of the obvious reasons for this could be that the level of coverage with individual vaccines does not meet the target of sustained high coverage required to control or eradicate disease. In 1980 s, the percentage of immunization was less than $5 \%$ according to the Govt figures. The campaign picked up in early 1990 sand the scenario changed rapidly as Govt took up the issue of national immunization [3]. In 1995-96, the immunization coverage was almost $91.7 \%$ for BCG, $91.6 \%$ for polio and $82.6 \%$ for measles. But, of late the trend has changed. With the launching of Pulse Polio Immunization programme (PPI) in 1995 to eradicate poliomyelitis, the routine immunization suffered. The fall in immunization coverage led to concerns of re-emergence of a few of these easily preventable killer diseases [4].

As there is some fall in immunization coverage of routine vaccines with the PPI programmes and disparity between Govt and UNICEF figures for immunization there is a definite need for a study to not only assess the coverage of immunization programme but also to study the socio demographic factors influencing the primary immunization rates and to know the reasons for partial immunization. The aim of the present study was to determine primary immunization coverage among children attending a Tertiary care hospital and to study the factors which influence the immunization status and the reasons for partial and non-immunization.

\section{Material \& Methods}

The present study was conducted in the Paediatrics' OPD and Children`s ward in Govt General Hospital, Rangaraya Medical College, Kakinada. The study was done from Jan 2012 to Sept 2013. It was a hospital based cross sectional study. Sample size was 2000. Parents attending with their children with age group 1-2 years were interviewed in the local language with the help of a proforma containing predesigned questionnaire. Data regarding demography, educational status of mother and father, parity, mode of delivery and birth weight were recorded. Details of immunization status of the child were recorded and the reasons for dropouts were noted. The child who received all primary doses of BCG, DPT, Hepatitis B, OPV and Measles as mentioned in National schedule was considered fully immunised. If child missed even a single dose as mentioned in the immunization schedule, is considered partially immunised. If the child has not received even a single dose of any vaccine is considered un-immunised.

\section{Results}

Out of 2000 children studied, 1810 were fully immunised (90.5\%), 186 were partially immunised (9.3\% - child received at least one of the UIP vaccines) and 4 of them were unimmunised (not received even a single vaccine)- (Table-1).

\section{Table - 1: Immunization coverage.}

\begin{tabular}{|l|l|l|}
\hline Immunization Status & Number & Percentage \\
\hline Completely immunised & 1810 & $90.5 \%$ \\
\hline Partially immunised & 186 & $9.3 \%$ \\
\hline Unimmunised & 4 & $0.2 \%$ \\
\hline
\end{tabular}

Data regarding various social and demographic factors influencing immunization coverage like gender, residence, type of family, religion, education of parents etc are shown in Table-2.

Our study showed that gender of the child, religion and residence of children had no significant role to play in the status of immunization coverage whereas type of family and education of parents had a significant role to play in the immunization coverage. Both male and female children almost had equal coverage with slight predominance in female children which is statistically insignificant. Similarly, immunization coverage is almost equal in children from rural and urban areas and is not statistically significant. Though percentage of Muslim children with full immunization coverage is less compared to children from other religions, this difference is not statistically significant. Immunization status is better in children coming from nuclear families than those coming from joint families which is statistically significant with a $\mathrm{p}$ value of $<0.05$. Maternal and paternal education had a significant role to play in the immunization status of children which is statistically significant with a $\mathrm{p}$ value of $<0.05$. 
Table -2: Socio-demographic factors influencing coverage.

\begin{tabular}{|c|c|c|c|c|c|}
\hline Status & Completely immunised & Partially immunised & Unimmunised & Total & $P$ value \\
\hline $\begin{array}{l}\text { Gender } \\
\text { Male } \\
\text { Female }\end{array}$ & $\begin{array}{l}974(90.35 \%) \\
836(90.67 \%)\end{array}$ & $\begin{array}{l}101(9.36 \%) \\
85(9.21 \%)\end{array}$ & $\begin{array}{l}3(0.27 \%) \\
1(0.1 \%)\end{array}$ & $\begin{array}{l}1078 \\
922\end{array}$ & $>0.05$ \\
\hline $\begin{array}{l}\text { Residence } \\
\text { Urban } \\
\text { Rural }\end{array}$ & $\begin{array}{l}449(90.7 \%) \\
1361(90.4 \%)\end{array}$ & $\begin{array}{c}46(9.3 \%) \\
140(9.3 \%)\end{array}$ & $4(0.3 \%$ & $\begin{array}{l}495 \\
1505\end{array}$ & $>0.05$ \\
\hline $\begin{array}{l}\text { Type of family } \\
\text { Nuclear } \\
\text { Joint }\end{array}$ & $\begin{array}{l}1171(91.99 \%) \\
639(87.9 \%)\end{array}$ & $\begin{array}{l}99(7.78 \%) \\
87(11.96 \%)\end{array}$ & $\begin{array}{l}3(0.23 \%) \\
1(0.14 \%)\end{array}$ & $\begin{array}{l}1273 \\
727\end{array}$ & $<0.05$ \\
\hline $\begin{array}{l}\text { Religion } \\
\text { Hindu } \\
\text { Muslim } \\
\text { Christian }\end{array}$ & $\begin{array}{l}1379(90.84 \%) \\
15(75 \%) \\
416(90.04 \%)\end{array}$ & $\begin{array}{l}136(8.96 \%) \\
5(25 \%) \\
45(9.74 \%)\end{array}$ & $\begin{array}{l}3(0.2 \%) \\
1(0.22 \%)\end{array}$ & $\begin{array}{l}1518 \\
20 \\
462\end{array}$ & $>0.05$ \\
\hline $\begin{array}{l}\text { Education of } \\
\text { parents } \\
\text { Literate mothers } \\
\text { Illiterate mothers } \\
\text { Literate fathers } \\
\text { Illiterate fathers }\end{array}$ & $\begin{array}{l}1331(94.5 \%) \\
484(81.1 \%) \\
1117(94.3 \%) \\
688(84.8 \%)\end{array}$ & $\begin{array}{l}77(5.5 \%) \\
109(18.2 \%) \\
67(5.7 \%) \\
119(14.7 \%)\end{array}$ & $\begin{array}{l}4(0.7 \%) \\
4(0.5 \%)\end{array}$ & $\begin{array}{l}1408 \\
597 \\
1184 \\
811\end{array}$ & $<0.05$ \\
\hline
\end{tabular}

Data regarding drop outs for various vaccines in male and female children is shown in Tabule-3. Drop outs for OPV, BCG and DPT were slightly more in male children whereas female children showed a slight predominance in measles vaccine dropouts as compared to male children.

Table 3: Percentage dropouts in male and female children.

\begin{tabular}{|l|l|l|l|}
\hline Vaccines & Male children N \% & Female children N \% & Dropout percentage in total dropouts \\
\hline OPV (0,1,2,3 doses) & $323 \%$ & $141.5 \%$ & $14.8 \%$ \\
\hline BCG & $90.8 \%$ & $70.75 \%$ & $5.1 \%$ \\
\hline DPT (1,2,3 doses) & $625.7 \%$ & $353.8 \%$ & $31.2 \%$ \\
\hline Measles & $817.5 \%$ & $717.7 \%$ & $48.9 \%$ \\
\hline
\end{tabular}

Out of total dropouts, measles vaccine constituted highest percentage with $48.9 \%$.Coverage and dropout rates of different vaccines is shown in the table-4.

Table 4: Coverage and dropout rates of various vaccines.

\begin{tabular}{|l|l|l|}
\hline Vaccine & Coverage No \% & Drop outs No \% \\
\hline BCG & 198499.2 & 160.8 \\
\hline OPV 0 & 199699.8 & 40.2 \\
\hline OPV 1 & 199799.85 & 30.15 \\
\hline OPV 2 & 198999.45 & 110.55 \\
\hline OPV 3 & 197298.6 & 281.4 \\
\hline DPT 1 & 198599.25 & 150.75 \\
\hline DPT 2 & 197198.55 & 291.45 \\
\hline DPT 3 & 194797.35 & 532.65 \\
\hline HEP B & 198799.35 & 130.65 \\
\hline HEP B 2 & 197198.55 & 291.45 \\
\hline HEP B 3 & 194097 & 603 \\
\hline MEASLES & 184892.4 & 1527.6 \\
\hline
\end{tabular}


BCG coverage was $99.2 \%$ whereas measles coverage was $92.4 \%$. There is a gradual drop out from BCG vaccine in neonatal period to measles vaccine at $9-10$ mo of age. Dropout rate from zero dose OPV to OPV 3 was minimal (1.2\%) whereas it is maximum from DPT 1 to measles $(6.9 \%)$.

Common reasons for dropouts were unwell child during the time of vaccination followed by no knowledge of vaccination and migration to other places with no knowledge of time and place of vaccination and misconceptions regarding vaccination(Table-5).

Table -5: Reasons for dropouts in primary immunization.

\begin{tabular}{|l|l|l|}
\hline Reason & Number & Percentage \\
\hline Unwell child & 58 & $27.5 \%$ \\
\hline No knowledge of vaccination & 53 & $25.12 \%$ \\
\hline Frequent migration with no knowledge of time and place & 37 & $17.5 \%$ \\
\hline Misconceptions & 30 & $14.2 \%$ \\
\hline Postponed because of laziness & 12 & $5.7 \%$ \\
\hline Non availability of vaccine & 12 & $5.7 \%$ \\
\hline Previous reactions to vaccine & 7 & $3.3 \%$ \\
\hline Polio vaccine is the only vaccine & 4 & $1.9 \%$ \\
\hline
\end{tabular}

\section{Discussion}

In the present study, we looked at adequacy of immunization coverage and reasons for partial and non immunization as immunization is a major and effective tool in fighting communicable diseases particularly in preventing childhood diseases. Accurate measurement of vaccination coverage is an essential step in determining expected reduction in mortality and morbidity from vaccine preventable diseases. Recent immunization coverage evaluation survey (2009) showed some improvement in the all India percentage in immunization coverage levels $(61 \%)$ [5]. National family health survey reported that proportion of completely immunised children had increased from $42 \%$ in $2^{\text {nd }}$ survey (1998) to $47.3 \%$ in $3^{\text {rd }}$ survey (20052006) [6]. But these figures vary widely across the regions, states and different strata of society depending on socio economic factors and availability of health care facilities. In our study, $90.5 \%$ of children are fully immunised which is slightly close to the study done by Dalal et al (85.3\%) [7] and Punit K et al (84.09\%) [8]. Compared to recent coverage evaluation survey by UNICEF in $2009(61 \%)$, our study shows better immunization (90.5\%). This may be because our study is hospital based and patients represent a wider section of population and different strata from all localities of East Godavari District who might be getting better health education compared to general population leading to better immunization coverage. Compared to other studies $[9,10]$, our study has increased coverage of different vaccines. But analysis of dropout rates shows that dropout rate is increasing with subsequent vaccination which is similar to other studies. This suggests that there is lack of sustained health education activity of the parents by the concerned health worker during their subsequent visits for immunization of their children.

Hepatitis B vaccine for infants was introduced nationwidein 180 countries by the end of 2011 . Global Hepatitis B coverage is estimated at $75 \%$ and is as high as $91 \%$ in the Western Pacific and $90 \%$ in the Americas and coverage in South East Asia region is around 56\% in 2011. WHO/UNICEF estimates of vaccine coverage in India in 2010 ranged from 21 - 37\% for Hepatitis B and remained at $72 \%$ for DPT3 coverage. There is a marked difference in the DPT3 and Hepatitis B 3 coverage in 3 successive years though the immunization of both the vaccines is scheduled at the same time. In our study, coverage of 3 doses of DPT (95.15\%) and 3 doses of Hepatitis B (94.9\%) is almost equal. This shows effective implementation of Hepatitis B vaccination in the immunization schedule along with DPT and increased health awareness regarding Hepatitis B vaccination in our locality.

There is no gender difference in immunization coverage in our study whereas in many studies $[11,12,13]$, there is significant male preponderance in immunization coverage which is indirect evidence for improvement in status of education, social and health care aspects of girl child in our locality. 
Our study shows that both urban and rural areas have almost equal coverage whereas other studies [14,15] had shown better coverage in urban areas. In the present study, children from nuclear families $(91.99 \%)$, Hindu and Christian communities (90.84\% and $90.04 \%$ ) are better immunised than those from joint families $(87.9 \%)$ and Muslim community (25\%) which is comparable to the study conducted by Malini Kar et al $[9,11,13]$. This may happen because conflicting opinions from different members of joint families may be an obstacle for immunization of children while in nuclear family only father and mother are directly involved in decision making. Low coverage in Muslim community shows that intervention programmes need to be tailored more specifically in them. Maternal literacy is important in because literate mother will have better understanding of the facts like when to start the immunization, how often child should be immunised and benefits of immunization. The status of children of literate mothers $(94.5 \%)$ in our study is comparable with other studies [7,11]. As per general assumption, mother plays a key role in taking children for immunization. It is not always true because though the mother has enough knowledge, father is the head of the family and he will decide regarding vaccination of their children. So father should be literate enough to make decision for the child's immunization. The studies done by Yadav et al and Dalal et al support the fact that father`s educational status has an important role to play in child's immunization which is statistically significant.

In the present study, the most common reasons for partial/no immunization are unwell child $(27.5 \%)$, no knowledge of vaccination $(25.12 \%)$, migration to other places with no knowledge of place and time of vaccination $(17.5 \%)$ and misconceptions (14.2\%). In addition to these reasons, fear of side effects and lack of motivation were found to be the reasons for under coverage in the other studies $[9,13]$. This variation in reasons for drop outs in different areas and different studies might probably be due to variation in the availability of health facilities and health monitoring system across the country.

Limitation of our study was that since data was taken only up to measles vaccination, immunization coverage reported in our study was high as compared to figures reported by others who had also considered booster doses of OPV \& DPT as part of immunization coverage. Some of the recommendations to improve immunization coverage are taking up education programmes in all antenatal, postnatal and immunization clinics, creating awareness like right age and time for immunization through IMNCI and IYCF, taking the help of mass communications like radio, TV and posters to increase awareness regarding routine immunization and to remove misconceptions in the general public. Health workers and medical personnel should educate the parents about the importance of routine immunization along with pulse polio immunization. Incentives can be offered to health workers who work with substantial interest and contribute to the improvement of immunization coverage. Every contact with health care personnel should be utilised to enquire about and educate the mothers regarding immunization of their children. Immunization status of children should be enquired by Anganwadi workers and school teachers during their admission into the schools. High dropout rate from BCG to measles vaccine indicates the need for sustained health education to ensure adequate coverage of all vaccines. In our study, still $1.9 \%$ of parents believed that polio vaccine is the only vaccine given to the child and $0.1 \%$ remained totally unimmunised. So Government has to take measures to increase literacy as it has direct correlation with immunization coverage and the number of health centres should be increased in all areas including tribal and hilly areas. Immunization coverage survey must be conducted at least once in a year by expert teams.

\section{Conclusions}

Though the coverage of different vaccines is high in our study and $90.5 \%$ children are completely immunised, the dropout rate is increasing with subsequent vaccination suggesting that there is lack of sustained health education activity of the parents by health workers.

The most common reasons for partial / no immunization are unwell child, lack of knowledge, migration to other places with no knowledge of place and time of vaccination and misconception. Hence urgent interventions to address the issues of both drop outs and poor accessibility and conducting regular IEC activities at all levels to increase the awareness of the mothers as well as all sections of the community regarding importance of completing all the vaccinations, is the need of the hour to achieve the goal of universal immunization of children against vaccine preventable diseases.

Funding: Nil, Conflict of interest: Nil Permission from IRB: Yes 


\section{References}

1.Kalaivani K, Mathiyazhagan T, Patro BC.Editorial. News Lett, Nat InstHlthFam Welfare.2006;8:1-2.

2.Park K. Principles of epidemiology and epidemiologic methods. Text Book of Preventive and Social Medicine Jabalpur, India. 2005:103.

3. www.childrendatabank.org/india/health/health5.htm 1 dt 11/10/09 18:15

4. Extract from express health care management. 2001; November1-15.

5. Coverage Evaluation Survey 2009 (CES-2009). A nationwide survey covering all states and union territories of India, Nov 2009 to Jan 2010, Commissioned by UNICEF.

6. National family Health Survey (NFHS-3), 2005-06International Institute for Population Sciences, Deonar, Mumbai

7. Dalal A, Silveira M. Immunization Status of children in Goa. Ind Pedatr.2005 Apr 17; 42:401-402.

8.Punith K, Lalitha K, Suman G, Pradeep BS, Jayanth Kumar K. Evaluation of primary immunization coverage of infants under universal immunization programme in an urban area of Bangalore city using cluster sampling and its lot quality. Indian $\mathrm{J}$ of Community Medicine.2008;33:151-5.
9. Kumar DVcDR, VK Agarwal D, HS Joshi D, Sharma MM. Evaluation of Primary immunization coverage in an urban area of Bareilly city using Cluster Sampling Technique. NJIRM.2010;1(4):10-15.

10. AM Khadri, Anjali Singh, Shikha Jain, R.G.Mahajan, Atul Trivedi. Study on Immunization coverage in urbanslums of Ahmedabad city.Health and Population: Perspectives and Issues. 2010;33(1):50-54.

11. Yadav RJ, Singh P. Immunization status of children and mothers in the state of Madhya Pradesh. Indian J Comm Med. 2004;29:147-148.

12. NirupamS. UIP in Sarojini Nagar Block of Lucknow District.Indian JComm Med.1991;16(2):82-4.

13. Malini Kar, VP Reddaiah, Shashi Kant. Primary Immunization Status of children in slum areas of South Delhi .IndJ.Comm Medicine 2001;26(3):151-154.

14. Dhadwal D, Sood R, Gupta AK, Ahluwalia SK, Vatsayan A, Sharma R. Immunization coverage among urban and rural children in Shimla hills. Ind J Comm Med. 1997;29(2):27-30.

15. Bashir Gaash, Rohini Bhan, Shabnam Bashir. Immunization status of infants in a remote district of Kashmir.Ind J Pediatrics. 2004; 1(3):11-12.

\section{How to cite this article?}

N Madhavi, D Manikyamba. Evaluation of immunization status and factors responsible for drop outs in primary immunization in children between 1-2 years - a hospital based study. Int J Pediatr Res 2016;3(5):329334.doi:10.17511/ijpr.2016.i05.10 